\title{
High Density Packaging of the Passive Components in an Automotive DC/DC Converter
}

\author{
Mark Gerber, Jan Abraham Ferreira, Ivan W. Hofsajer, Member, IEEE, and Norbert Seliger
}

\begin{abstract}
In this paper, a very high power density dc/dc converter module for automotive applications is investigated. The 14-V/42-V converter is specified to operate at a power level of $2.1 \mathrm{~kW}$ with a water cooled heat sink at $85{ }^{\circ} \mathrm{C}$. The design and implementation of very high density passive components are discussed. Using the results of the passive component design, a prototype converter is built, achieving a final power density of $170 \mathrm{~W} / \mathrm{in}^{3}$. The thermal performance of the passive components and the converter module under different electrical and thermal excitations is investigated and recorded. Results are presented over the full excitation range.
\end{abstract}

Index Terms-Converter module, thermal performance.

\section{INTRODUCTION}

$\mathbf{I}$ $\mathrm{N} 1965$, the nominal voltage of the automotive powernet was doubled from $6 \mathrm{~V}$ to $12 \mathrm{~V}$ in response to the increasing requirements of the automotive electrical systems [1], [2]. Today, the nominal voltage level of the powernet is about to be tripled for the same reason [1], [2]. Unfortunately, it will take a great deal of time to perform this conversion due to the complexity of the modern-day automotive system. As an intermediate step, both the $14-\mathrm{V}$ and $42-\mathrm{V}$ systems will be implemented [1]. Fig. 1 shows a possible implementation of such a powernet configuration.

The 14-V section of the powernet will provide power to the low power applications within the automobile. This will typically include the light bulbs, the microelectronics and so forth. The 42-V section of the powernet will power the new applications that are being implemented. These will typically include electronically aided steering, electronically aided brakes and so forth.

There are several other configurations possible with different layouts, but they all have the bi-directional dc/dc converter in common. This converter is required to allow the controlled power transfer between the power cells at the different voltage levels [1]. Power can also be transferred between the different voltage levels during events such as starting.

Manuscript received October 22, 2002; revised April 28, 2004. Recommended by Associate Editor M. C. Shaw.

M. Gerber and J. A. Ferreira are with the Faculty of Electrical Engineering, Mathematics and Computer Science, EWI Faculty, Delft Technical University, Delft 2600 GA, The Netherlands (e-mail: m.gerber@ewi.tudelft.nl; j.a.ferreira@ewi.tudelft.nl).

I. W. Hofsajer is with the Industry Electronics Technology Research Group, The Rand Afrikaans University, Auckland Park 2006, Republic of South Africa (e-mail: iwh@ing.rau.ac.za; iwh@ieee.org).

N. Seliger is with the Corporate Technology Department, Siemens AG, Munich D-81730, Germany (e-mail: norbert.seliger@mchp.siemens.de).

Digital Object Identifier 10.1109/TPEL.2004.843020

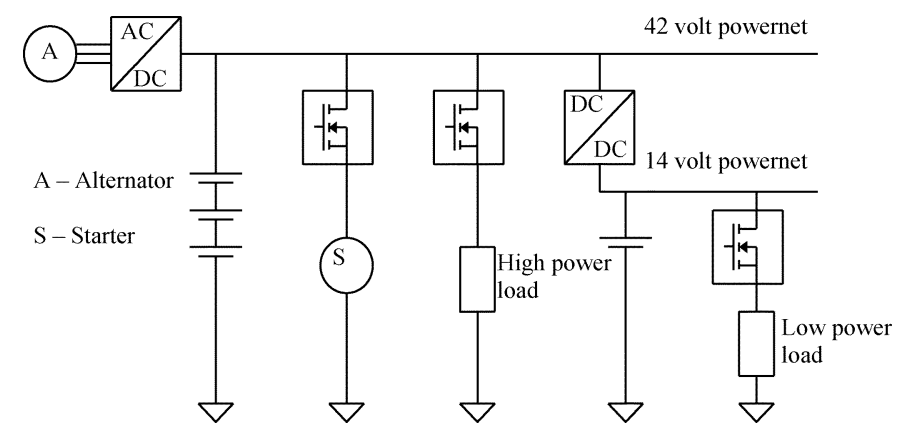

Fig. 1. Possible powernet configuration.

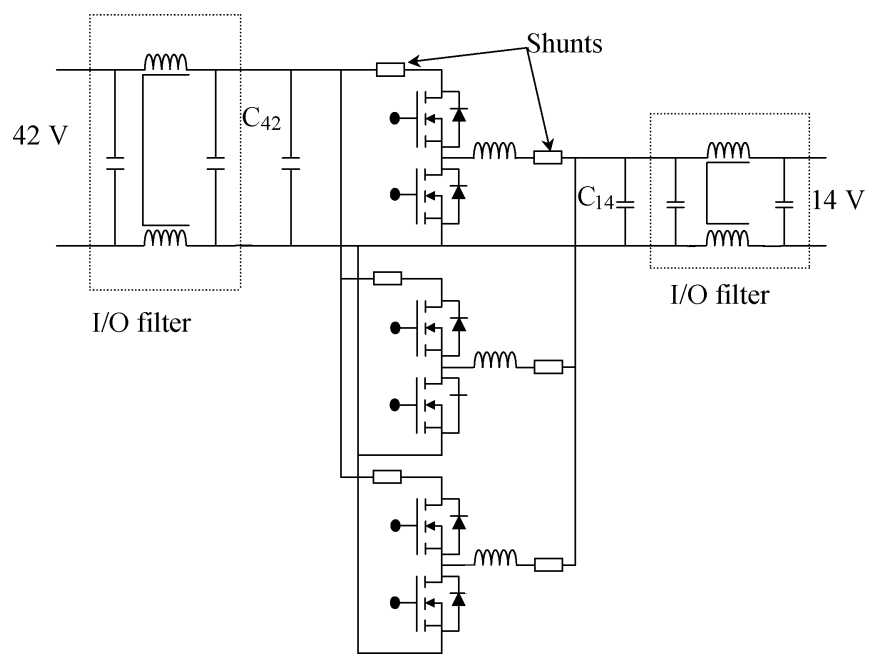

Fig. 2. Implemented converter topology.

This dc/dc converter, together with the design and implementation of high power density passive components, forms the main focus of this paper. A prototype converter is designed and built, based on the results of the high power density passive component design. The high power density requirement is driven by the space restrictions of the final operating environment. The converter will typically be located within the engine compartment of the vehicle requiring the converter to operate within a limited volume and a high ambient temperature environment.

\section{IMPLEMENTED CONVERTER}

The dc/dc converter topology is illustrated in Fig. 2. The converter consists of three bi-directional phase arms that are time interleaved to produce reduced capacitor current ripples at the converter terminals [2], [5]. In the topology, six shunt resistors 
TABLE I

CONVERTER COMPONENTS AND OPERATING VALUES

\begin{tabular}{c|c}
\hline Parameter & Value \\
\hline $\mathrm{I}_{42}$ & $50 \mathrm{~A}$ \\
\hline $\mathrm{I}_{14}$ & $150 \mathrm{~A}$ \\
\hline Switching frequency $\mathrm{f}_{\mathrm{s}}$ & $170 \mathrm{kHz}$ \\
\hline Inductor & $2.2 \mu \mathrm{H}$ \\
\hline Bus capacitors & $10 \mu \mathrm{F}$ \\
\hline $\begin{array}{c}\text { Filter common mode } \\
\text { inductance }\end{array}$ & $2.5 \mu \mathrm{H}$ \\
\hline
\end{tabular}

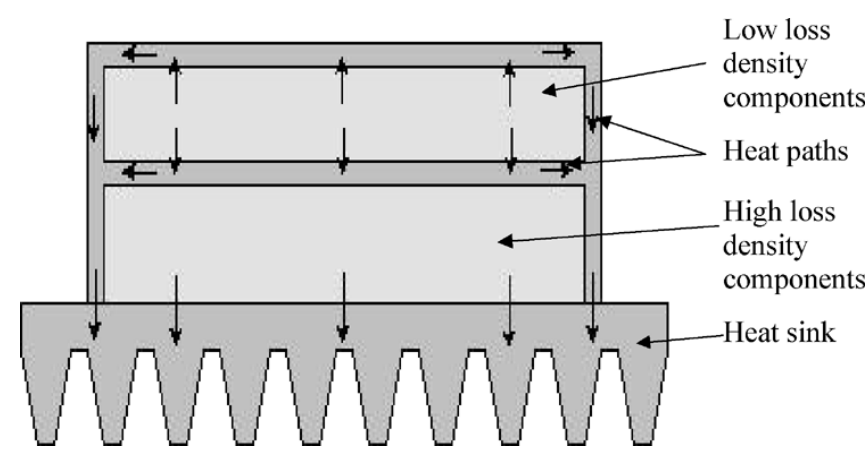

Fig. 3. Integrated heat sink is used to conduct heat from the passive components.

have been included. The shunts are required for current measurements required by the control circuit, which will not be discussed in this paper. The filters at the converter terminals are required to help contain any EMI that the converter produces [7].

Table I lists the main operating variables and component values for the converter based on the specification of $2.1 \mathrm{~kW}$ and a water cooled heat sink with the coolant at $85^{\circ} \mathrm{C}$.

\section{ENVISAGED SOLUTION}

The primary driver for the packaging is that the converter must have as high a power density as possible. However, the packaging of the converter, and thus, the power density, is greatly influenced by the available cooling [3], [4]. With the heat removed from the components in an effective, volume saving manner, a high power density can be achieved. Based on this interdependence between packaging, cooling and power density, a conceptual solution to the packaging of the converter is proposed in Fig. 3.

The converter is to be mounted on a water cooled heat sink at $85{ }^{\circ} \mathrm{C}$. In this application, the heat sink can be considered to be infinite in capacity. The temperature of the converter base is therefore constant, irrespective of the amount of heat transmitted to the heat sink.

Fig. 3 shows the infinite heat sink with two chambers above the heat sink. The walls of the chambers are thermally conductive, creating two regions in which heat is either conducted directly into the infinite heat sink or into the walls and then into the heat sink. This concept is referred to as integrated heat sinking [6].

The lower chamber has direct contact with the infinite heat sink. For this reason, the converter components that produce the most losses are placed in this chamber. These are typically the

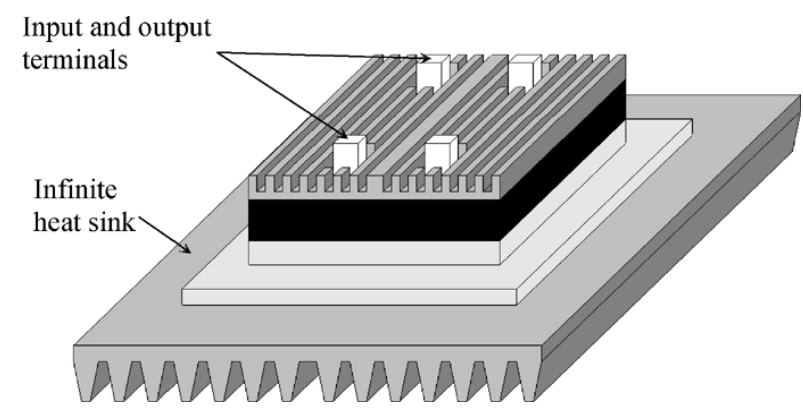

Fig. 4. Packaging objective.

TABLE II

INDUCTOR REQUIREMENTS AND CHARACTERISTICS

\begin{tabular}{c|c}
\hline Property & Value \\
\hline Inductance & $2.2 \mu \mathrm{H}$ \\
\hline Average current & $50 \mathrm{Amps}$ \\
\hline Ripple current & $25 \mathrm{Amps}( \pm 12.5 \mathrm{Amps})$ \\
\hline Operating frequency & $170 \mathrm{kHz}$ \\
\hline Number of turns & 2 \\
\hline $\mathrm{B}_{\max }(3 \mathrm{~F} 3)$ & $245 \mathrm{mT}$ \\
\hline $\mathrm{A}_{\text {core }}$ & $280 \mathrm{~mm}^{2}$ \\
\hline
\end{tabular}

semi-conductors having very high loss densities. Since the physical distance between the infinite heat sink and the components will be very short, the components, with the correct mounting, will have low thermal resistances preventing the materials from exceeding their maximum temperatures.

The upper chamber has a much larger distance between the components and the infinite heat sink. Consequently, the thermal resistance between components in this chamber and the infinite heat sink will be larger because the heat must be conducted to the heat sink via the walls. Thus, less heat can be conducted away from the chamber for a given temperature rise than for the lower chamber. Due to the larger thermal resistance, low loss components can be placed in this chamber without exceeding their maximum temperatures. Typical components implemented in this chamber are the passive components such as the inductors.

The goal that the packaging structure is attempting to achieve is illustrated in Fig. 4. The final converter structure is to be a self-contained, thermally optimized structure. The gate drives of the converter are also to be included in the structure.

\section{High Density PAssive COMPONENTS-ThE INDUCtoR}

An inductor structure to be implemented in the upper chamber is considered. The inductor is required to operate within the high temperature environment without exceeding the material's maximum operating temperatures. All the heat generated in the inductor is to be conducted to an infinite heat sink with a constant temperature of $85{ }^{\circ} \mathrm{C}$. Only thermal conduction is considered as part of the cooling due to the operating environment in which the inductor will be implemented.

Table II lists some of the inductor properties and operating conditions. The inductor is implemented with a two-turn planar structure. A planar structure was chosen as the base from which 


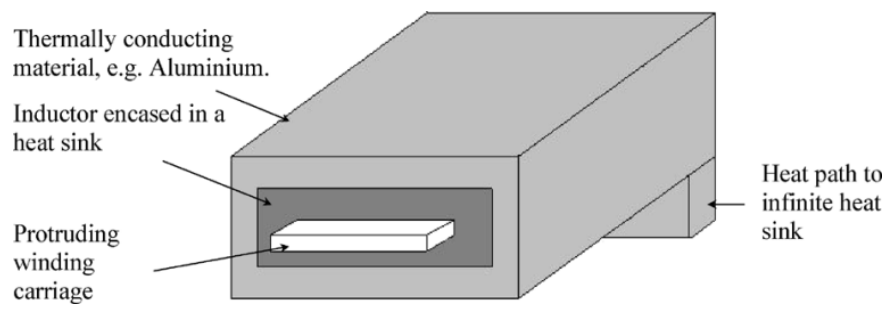

Fig. 5. Planar inductor encased in a heat sink.

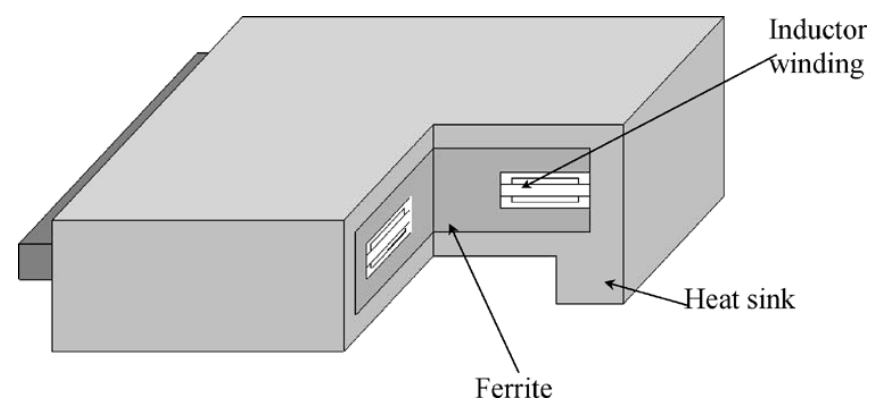

Fig. 6. Indirect heat removal structure.

to work due to the structure's increased surface area allowing for better heat conduction [7].

\section{A. Inductor Cooling Structure}

The heat generated in the inductor structure must be conducted away from the inductor structure. To maximize the conducted heat, the entire inductor structure is encased in an aluminum heat sink, as illustrated in Figs. 5 and 6. Only the winding connections protrude from the front of the inductor structure. The heat sink at the back of the structure is extended down to the infinite heat sink. This extension forms a heat path between the inductor and the infinite heat sink as discussed in the previous section. It is assumed that this heat path is the only way for the heat to be removed from the inductor.

The inductor is implemented with a ferrite core. There will be magnetic flux leakage out of the core at any irregularity and into the heat sink material. This leakage flux will interact with the heat sink inducing eddy currents, and consequently additional losses. To determine the validity of the proposed heat removal method, the interaction between the inductor structure and the heat sink is investigated. Fig. 6 shows the section used in the two-dimensional FEM analysis to determine the magnetic field density distribution. This is in turn is used to determine inductor losses.

\section{B. Inductor Simulations}

The contour representation of the magnetic flux density in Fig. 7, for the high frequency current, indicates that the magnetic flux in the distributed gap, is divided into two parts that flow around the distributed gap. Eddy currents are induced in both the copper winding and the heat sink due to fringing.

The eddy currents will be orientated according to Lenz's law in such a way that their magnetic fluxes oppose the initially applied magnetic flux. The two fluxes will summate and the result is that in the distributed gap, the two magnetic fluxes oppose
1

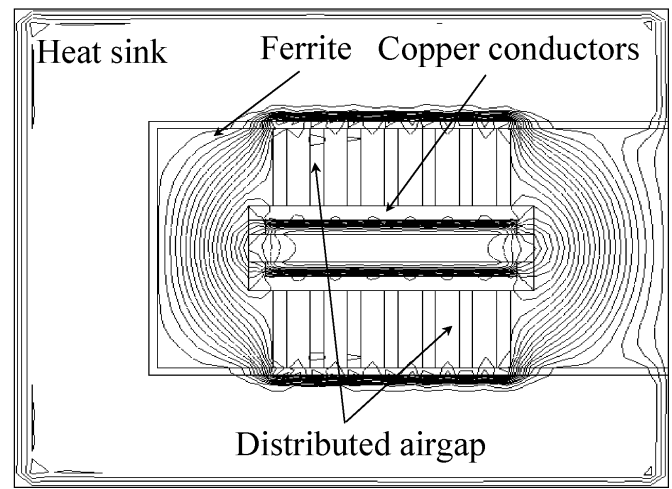

Fig. 7. The FEM analysis of the winding window cross-section.

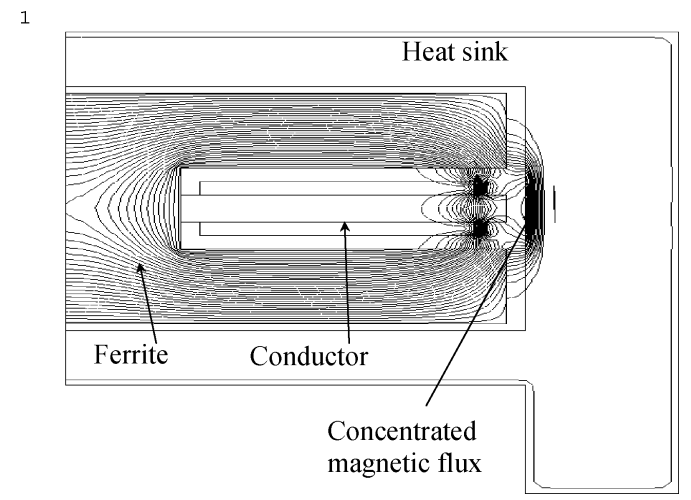

Fig. 8. FEM analysis of the conductor perpendicular to the winding window within the heat sink.

each other, causing the magnetic flux density to be reduced. Outside the gap, above and below, the induced magnetic flux and the initially applied magnetic flux will summate, causing the magnetic flux density to be higher.

Fig. 8 shows the result of the magnetic flux density distribution simulation for the winding structure within the heat sink using the same electrical excitation as for the previous simulations. The simulation shows that the magnetic flux leaks into the heat sink in a very localized position in both the conductors and the heat sink. The high frequency magnetic flux density will induce eddy currents in both the copper conductors and the heat sink. In the heat sink, the eddy currents are localized in the same region as the magnetic flux density. These currents will result in losses in the material, consequently heating the material in a localized spot. In the copper conductor, the induced currents will interact with the inductor current, resulting is a poor current distribution in this section of the winding. As a result, the losses in both materials will be increased.

\section{Thermal Simulation}

The losses determined for the inductor structure are used to perform a thermal simulation to determine the effectiveness of the heat path structure. The simulation result is plotted for half of the inductor structure in Fig. 9.

The simulation shows that the maximum temperature within the inductor structure does not exceed the infinite heat sink temperature by more than $10{ }^{\circ} \mathrm{C}$. The simulation was performed 


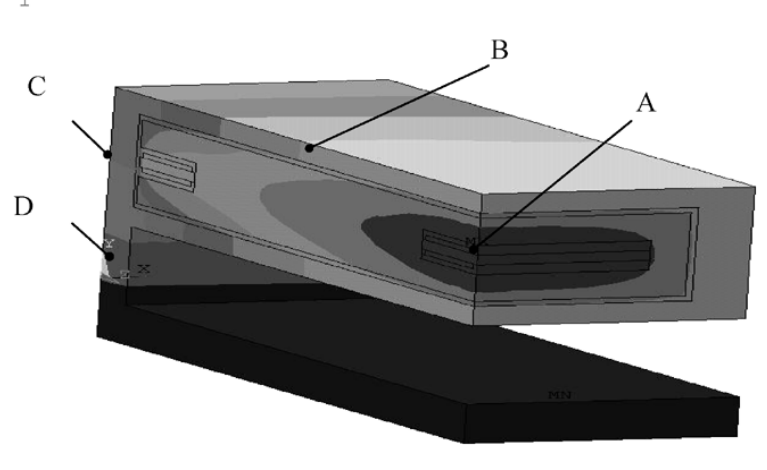

Fig. 9. Thermal analysis of the inductor structure.

TABLE III

MEASURED AND SimUlated TEMPERATURES

\begin{tabular}{c|c|c}
\hline Point & Simulated $\left({ }^{\circ} \mathrm{C}\right)$ & Measured $\left({ }^{\circ} \mathrm{C}\right)$ \\
\hline A & 92.5 & 93 \\
\hline B & 89.5 & 89.5 \\
\hline C & 87.8 & 87.5 \\
\hline D & 85.8 & 86 \\
\hline
\end{tabular}

with an infinite heat sink temperature of $85^{\circ} \mathrm{C}$ and the maximum temperature expected on the copper conductor is approximately $92.5^{\circ} \mathrm{C}$.

To verify these results, a prototype inductor structure was built and excited under the simulation conditions. The temperature was measured at several points on the structure as indicated in Fig. 9. The heat sink temperature measurements were made with small thermistors calibrated against a PT1000 calibration probe. The thermistors were placed in small holes in the heat sink to ensure accurate temperature measurements. The measured and simulated results are summarized in Table III. The results show good correlation between measured and expected results, confirming the effectiveness of the proposed heat removal structure.

The heat path described here is used together with the integrated heat sink structure in the converter structure to be considered next.

\section{CONVERTer Module}

In the following sections, more attention is paid to the implementation, realization and evaluation of the converter module. The previously considered inductor structure forms a significant portion of the converter module, as will be discussed.

\section{A. Thermal Management}

Fig. 10 shows a cross section through the conceptual converter structure. The figure shows the relative positioning of the active and passive components within the integrated heat sink structure. The phase arms with the high loss density components are implemented on the base, in the lower chamber of Fig. 3, with the low loss density components, such as the inductor, implemented in the upper chamber, above the active components.

Furthermore, the inductor heat sink is in thermal contact with the capacitors providing a path to remove the heat of the capacitors. The heat generated in the inductor structure and capacitors

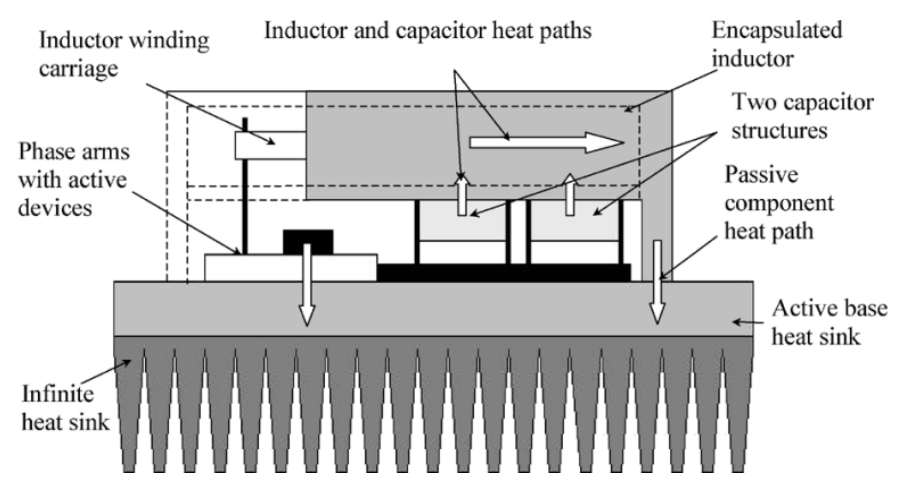

Fig. 10. Heat paths in the conceptual converter.

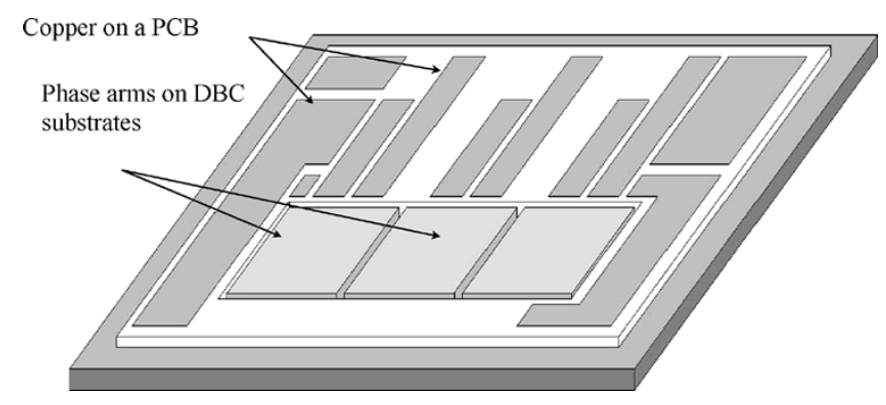

Fig. 11. Conductor layout on the active base.

is conducted to the infinite heat sink through the back wall of the converter structure.

In the figure, the heat paths for the different heat sources are identified. This clearly illustrates how the heat sink structure is used to conduct the heat away from all the loss sources. This also illustrates how the cooling method largely determines the packaging form and the density.

\section{B. Module Realization}

In this section, the construction of the converter is briefly described. Fig. 11 shows the base, on which the converter is built, with only the copper conductors in place. The copper conductors are implemented with both DBC and conventional printed circuit board (PCB).

The DBC structures are used to implement the three phase arms. The semi-conductor devices on the DBC structures are implemented with open die devices each with a maximum operating temperature of $170{ }^{\circ} \mathrm{C}$. This is done to take advantage of the superior thermal performance that DBC offers [3]. The three DBC substrates are labeled in the figure. The remaining conductors are implemented with copper foil, $1 \mathrm{~mm}$ thick soldered onto a PCB carrier. The PCB is used primarily to keep the conductors in place and the copper foil is used to reduce the current density on the PCB to an acceptable level.

Fig. 12 shows the two capacitor structures placed on top of the base structure. The two capacitor structures are implemented with several high temperature polypropylene metal film capacitors soldered onto vertical conductors. The vertical conductors are used as bus bars to connect the relative conductors on the base to the terminal connections on either side of the base. The capacitor at the front of the structure is the $14-\mathrm{V}$ bus capacitor and the capacitor at the back is for the $42-\mathrm{V}$ bus. Both of the 


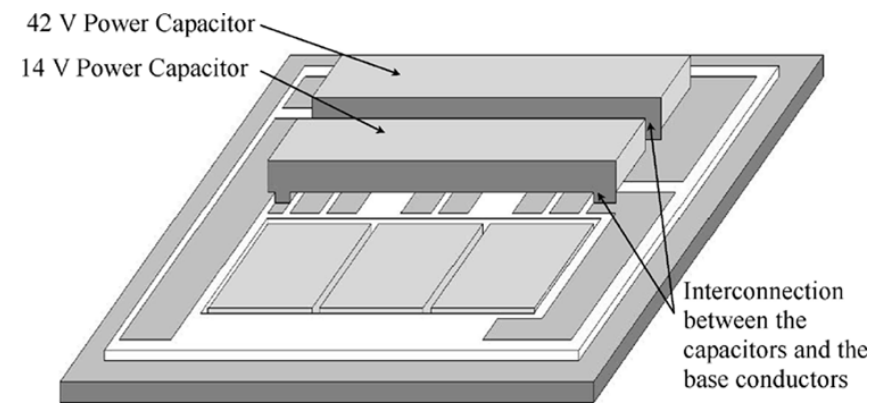

Fig. 12. Placement of the two converter capacitors.

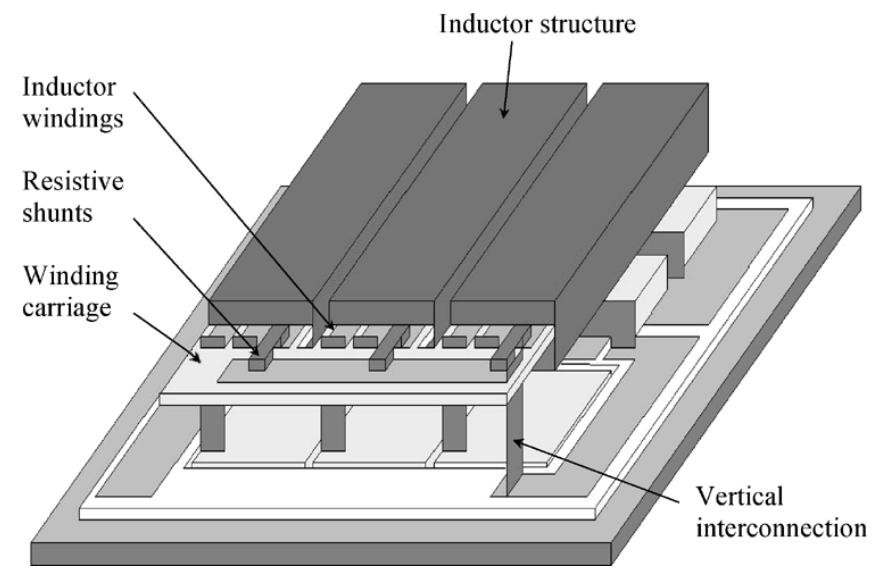

Fig. 13. Placement of the three inductor structures.

capacitors are in thermal contact with the integrated heat sink, but they are electrically isolated.

Fig. 13 shows the active base with the three inductor structures placed above the capacitor structures. The inductor structures are sized so that the three structures next to each other have the same width as the three phase arms. The length of the inductors extends to the back of the two capacitors. The inductors are implemented with a two-turn planar structure. A distributed air gap is used to help reduce the inductor losses [9]. The figure also shows the connections between the three phase arms and the three inductors.

The inductors are connected to the phase arms via vertical connections. The vertical connections pose several implementation problems such as connecting the orthogonal conductors with low thermal resistances and large current densities. To overcome these problems, the connections are made to be as short as possible by placing the inductor connection point directly above the phase arm and allowing for a large contact area to the base on the infinite heat sink to reduce the thermal resistance. Furthermore, the three inductors are connected to a common conductor also shown in the figure. The connection between the inductors and the conductor is made with the surface mount shunt resistor to provide for the current measurement. The common conductor operates with a current density of $17 \mathrm{~A} / \mathrm{mm}^{2}$. To ensure the conductor does not reach a very high temperature, the thermal resistance is lowered by using a very large contact area between the vertical conductor and the base.

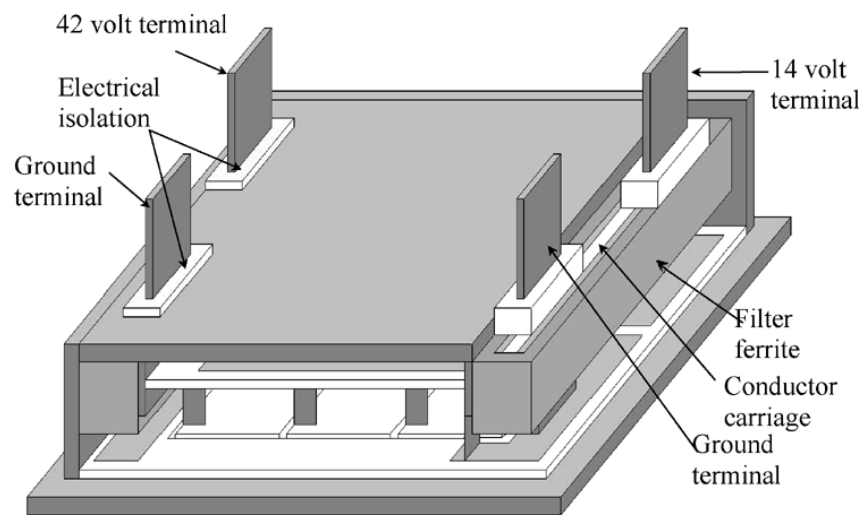

Fig. 14. Location of the two filters and the integrated heat sink.

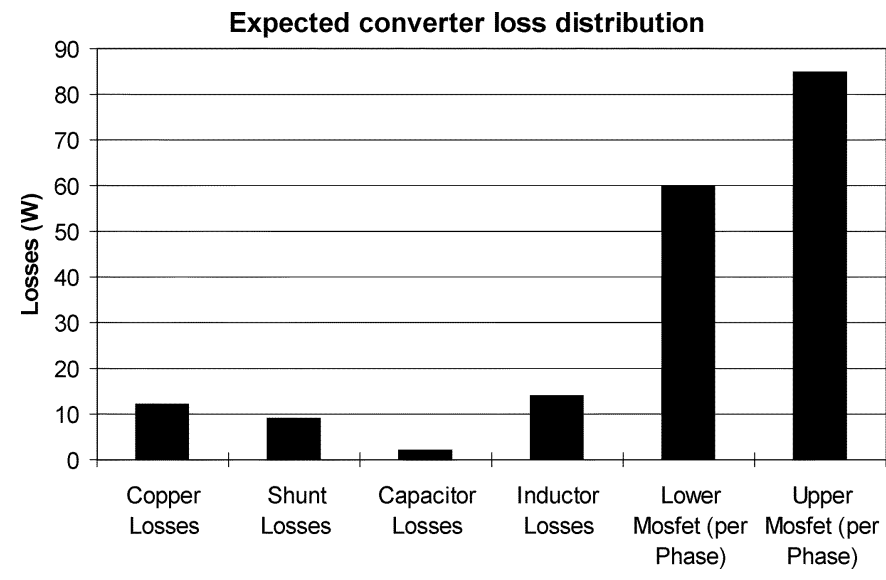

Fig. 15. Expected loss distribution in the converter structure under full thermal and electrical load.

Fig. 14 shows the converter structure with the integrated heat sink and the two filter structures in place. The two filters are extensions of the converter terminals. On either side of the converter, contact terminals are implemented with large cross-section conductors. By making the conductors planar and placing them parallel to each other, some filtering effect can be achieved [8]. However, for an almost negligible increase in the volume, the filtering effect can be significantly increased by the inclusion of a ferrite ring around the two parallel terminal conductors. This allows for the implementation of two filters in the form of common mode inductors. However, due to the nature of the structure, some differential filtering is also obtained [8].

\section{THERMAL MODELLING}

The converter is to operate at a high ambient temperature in a highly compact structure. To ensure the designed converter does not overheat, a thermal simulation was performed, based on the expected losses for the different sections of the converter.

\section{A. Expected Converter Losses}

To determine the losses of the different parts of the converter structure, several experiments were performed. The losses were determined both theoretically and experimentally for the different components. The expected loss distribution within the converter structure operating at full electrical and thermal load is illustrated in Fig. 15. 


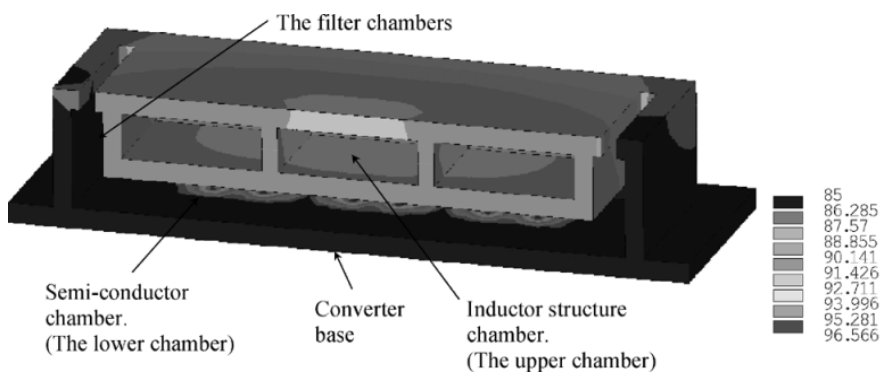

Fig. 16. Section of the simulated converter structure.

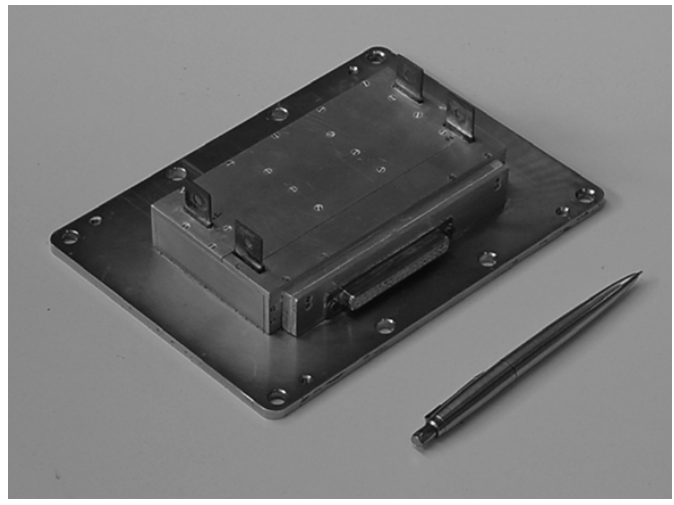

Fig. 17. High power density dc/dc converter.

The loss distribution in Fig. 15 summarizes the total structure losses with the exception of the metal oxide semiconductor field effect transistor (MOSFET) losses on the right of the figure. The MOSFET losses are shown for only one of the three phases. The copper losses, shunt losses, capacitor losses and inductor losses are all for the entire structure. The total converter loss is expected to be about $450 \mathrm{~W}$ with an output power of $2.1 \mathrm{~kW}$ giving an expected efficiency of approximately $81 \%$.

From Fig. 15, it can be seen that $90 \%$ of all the losses are expected to be in the MOSFETs. This is due to the high switching losses in the upper phase arm device and the reverse recovery losses of the MOSFET body diode during commutation [4], [5].

\section{B. Thermal Simulation}

Fig. 16 shows one of the thermal simulation results. The figure shows a section through the converter structure. Only the heat sink material is shown. From the figure, the temperature gradients can be seen by the changing shades. These indicate that heat is being conducted away from the passive components as expected.

\section{EXPERIMENTAL RESULTS}

The implemented dc/dc automotive converter is illustrated in Fig. 17. The converter dimensions are: width $=130 \mathrm{~mm}$, depth $=70 \mathrm{~mm}$ and height $=21 \mathrm{~mm}$. The two terminals on the left of the figure are for the $42-\mathrm{V}$ connection and on the right for the $14-\mathrm{V}$ connection. The converter is mounted onto an infinite heat sink by the eight mounting holes. The connector in front of the converter allows access to the internal gate drives.

Fig. 18 shows the internal components of the converter structure. In the bottom left corner, the active base can be seen. The

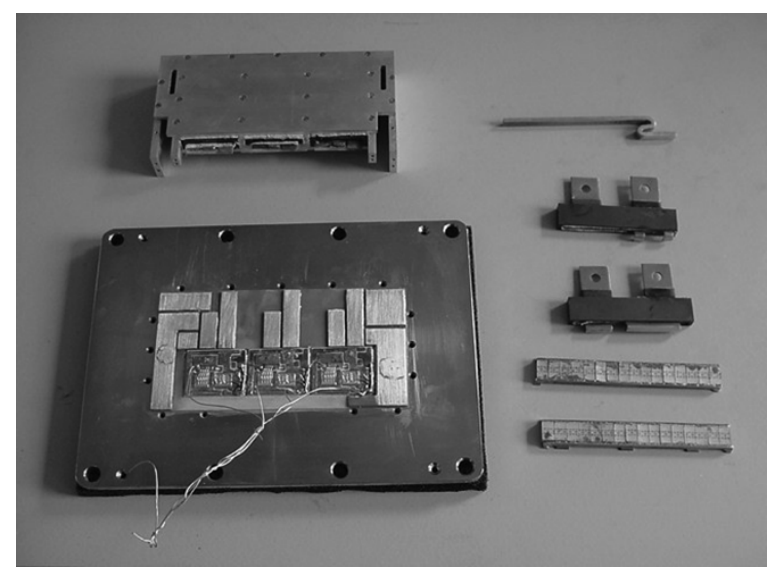

Fig. 18. Components of the high power density converter.

base shows the DBC structures with the six open die MOSFETs. The remaining conductors are implemented on the PCB as previously discussed.

In the top left of the figure, the three inductor structures mounted in the integrated heat sink structure can be seen. This section of the converter is mounted on top of the active base. The heat sink structure is implemented with several heat sink sections to realize the complicated heat sink structure. The heat sink structure is extended to include the filters on either side of the three inductors.

In the top right corner, the 150-A bus bar can be found. The conductor connects the three inductors and then connects the inductors to the $14-\mathrm{V}$ terminal. The conductor operates with a current density of $17 \mathrm{~A} / \mathrm{mm}^{2}$. However, due to the low thermal resistance between the conductor and the heat sink, the conductor does not overheat.

Below the conductor, the two common mode filters can be seen. The filters, as previously described, utilize the already present conductors to implement filters with the aid of additional ferrite rings.

In the bottom left of the figure, the two capacitor structures can be seen. The capacitors are implemented with low profile metal film capacitors. The capacitors have a large capacitance density while operating at high temperatures. The capacitor structures are made to have a large surface area so as to ensure a low thermal resistance between the capacitors and the inductor heat sink.

Fig. 19 shows the measured waveforms for one of the converter phase arms. The figure shows the inductor current and the drain-to-source voltage of the lower MOSFET. The measurements were taken under full electrical and thermal excitation into a resistive load.

Fig. 20 plots the measured converter efficiency over the full power and temperature operation range. The efficiency is plotted for operation with an infinite heat sink cooled with water at $20^{\circ} \mathrm{C}, 60^{\circ} \mathrm{C}$, and $85^{\circ} \mathrm{C}$. In the figure the theoretical efficiency is also displayed by an "X." The theoretical efficiency is just over $81 \%$ at full electrical and thermal load, and it is determined from Fig. 15 for a $2.1-\mathrm{kW}$ output power.

The figure shows that as the power level increases, the efficiency decreases. This is expected due to the square relationship between the current and conduction resistance. The figure also 


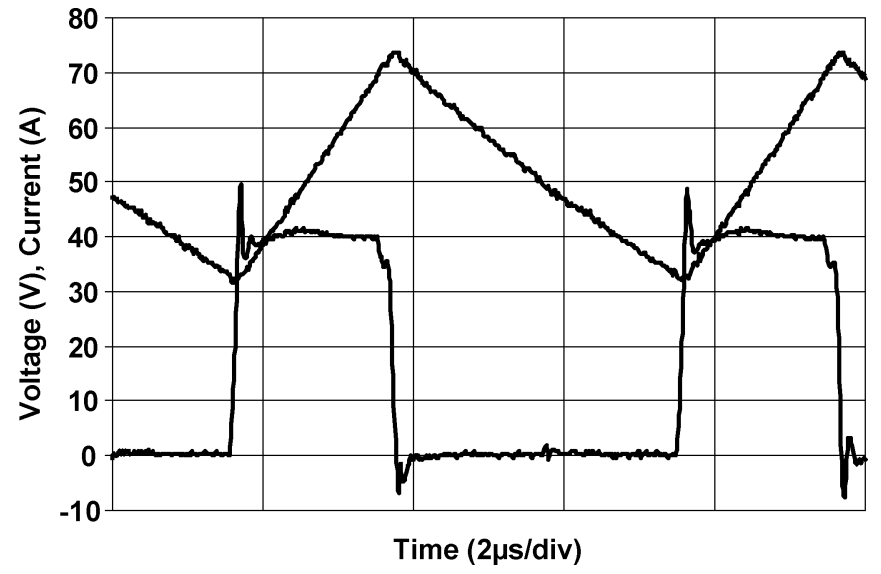

Fig. 19. Waveforms of one of the three phase arms.

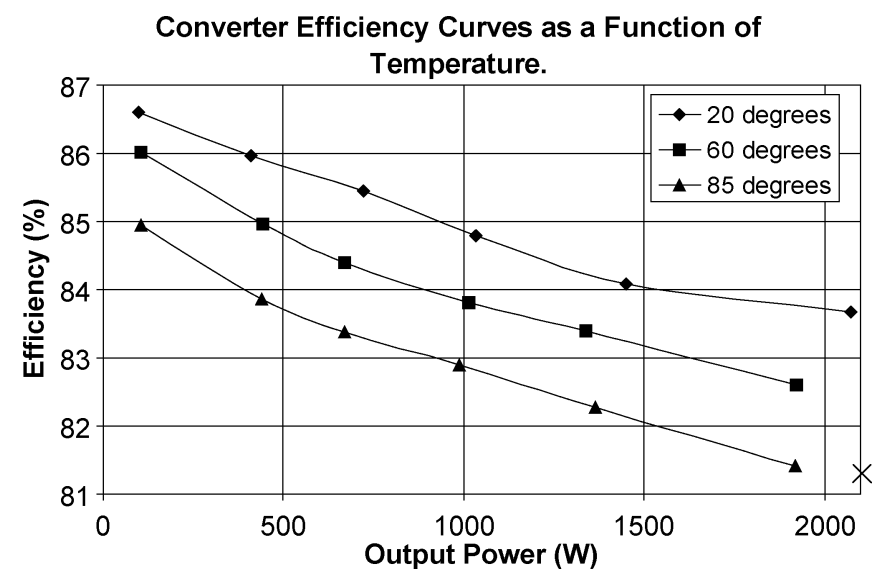

Fig. 20. Converter efficiency as a function of coolant temperature and output power.

shows that for a given operating point, the efficiency decreases as the infinite heat sink temperature increases. This is again expected due to the temperature-dependent loss mechanisms such as electrical conductivity. The measured efficiency corresponds well to the expected losses as indicated in the figure.

\section{CONCLUSION}

In this paper, the construction and implementation of a high power density dc/dc converter for automotive applications were discussed.

The thermal management of the converter was considered. The thermal management was vital in the design stage of the converter since the cooling of the converter determine many packaging limitations. For example, only thermal conduction could be used to cool the structure. This has many consequences for both the materials used and the geometry of the structures.

As part of the thermal management considerations, the packaged inductor structure was considered by itself. The inductor structure indicated the effectiveness of the proposed thermal management system. The inductor structure was also built and evaluated.
The converter structure was built and tested under full thermal and electrical excitation and met all the specifications. Under full load operation at $85^{\circ} \mathrm{C}$, all the material temperatures were within the safe operating temperature for each material.

The power density achieved for the converter is $10.5 \times 10^{6} \mathrm{~W} / \mathrm{m}^{3}\left(170 \mathrm{~W} / \mathrm{in}^{3}\right)$. This power density level far exceeds the highest power density that can be found in literature for this application. Furthermore, if the coolant temperature is decreased, the power density can be increased further.

\section{REFERENCES}

[1] J. Neubert, "Powering up," Inst. Elect. Eng. Rev., pp. 21-25, Sep. 2000.

[2] T. J. Schoepf and W. F. Rieder, "Consequences for automotive relays of a 42 VDC power network in vehicles," IEEE Trans. Compon. Packag. Technol., vol. 23, no. 1, pp. 177-182, Mar. 2000.

[3] J. Schulz-Harder, "DBC substrates as a base for power MCM's," in Proc. 3rd Electronics Packaging Technology Conf. (EPTC'00), 2000, pp. 315-320.

[4] S. Deuty, "Optimising transistor performance in synchronous rectifier buck converters," in Proc. Applied Power Electronics Conf. Expo (APEC'O0), vol. 2, 2000, pp. 675-678.

[5] C. S. Mitter, "Device considerations for high current, low voltage synchronous buck regulators (SBR)," in Proc. Wescon'97 Conf., 1997, pp. 281-288.

[6] R. J. Huljak, V. J. Thottuvelil, A. J. Marsh, and B. A. Miller, "Where are power supplies headed?," in Proc. 15th Annu. IEEE Applied Power Electronics Conf. Expo, vol. 1, 2000, pp. 10-17.

[7] I. W. Hofsajer, J. A. Ferreira, and J. D. van Wyk, "A new manufacturing and packaging technology for the integration of power electronics," in Proc. Industry Applications Annu. Meeting, vol. 1, 1995, pp. 891-897.

[8] S. J. Marais, J. A. Ferreira, and J. D. van Wyk, "Planar integrated output filters for hybrids [SMPS]," in Proc. Power Electronics Specialists Conf., vol. 2, 1997, pp. 1143-1149.

[9] H. Jiankun and C. R. Sullivan, "The quasidistributed gap technique for planar inductors: design guidelines," in Proc. Industry Applications Annu. Meeting, vol. 2, 1997, pp. 1147-1152.

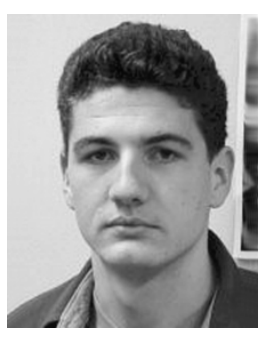

Mark Gerber received the B.S. and M.S. degrees in electrical and electronic engineering from the Rand Afrikaans University, Johannesburg, South Africa, in 1999 and 2001, respectively, and is currently pursuing the Ph.D. degree at the Technical University of Delft, Delft, The Netherlands.

$\mathrm{He}$ is conducting research into the issues surrounding high temperature packaging of power converters. His main interests include $\mathrm{dc} / \mathrm{dc}$ converters and the packaging there of.

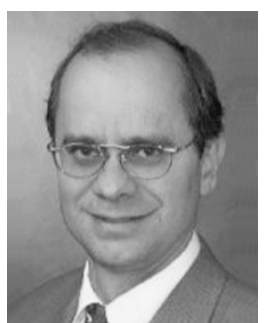

Jan Abraham Ferreira was born in Pretoria, South Africa. He received the B.Sc.Eng., M.Sc.Eng., and $\mathrm{Ph} . \mathrm{D}$. degrees in electrical engineering from Rand Afrikaans University, Johannesburg, South Africa, in 1980, 1982, and 1988, respectively.

He was with ESD(Pty), Ltd., from 1982 to 1985. From 1986 to 1997, he was with the Faculty of Engineering, Rand Afrikaans University, where he held the Carl and Emily Fuchs Chair of Power Electronics. Since 1998, he has been a Professor at the ITS Faculty, Delft University of Technology, Delft, The Netherlands. He has co-authored more than 150 publications in power electronics.

Dr. Ferreira is the Transactions Review Chairman of the IEEE IAS Power Electronic Devices and Components Committee. He is Founding Chairman of the IEEE Joint IAS/PELS Benelux Chapter, is also a Member of the IEEE PESC Adcom, and a member of the Executive Committee of the EPE Society. 


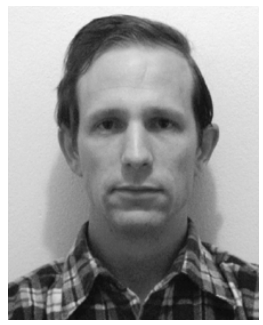

Ivan W. Hofsajer (M'93) was born in Johannesburg, South Africa. He received the B.Ing., M.Ing., and D.Ing. degrees in electrical engineering from the Rand Afrikaans University, Johannesburg, in 1991, 1993, and 1998, respectively.

$\mathrm{He}$ worked at the South African Atomic Energy Corporation in the field of electromagnetic interference. At present, he is a Senior Lecturer in the Department of Electrical and Electronic Engineering, Rand Afrikaans University. His interests include power electronics and electromagnetics.

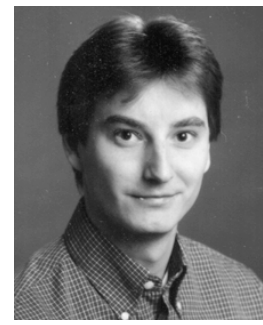

Norbert Seliger received the Ph.D. degree in electrical engineering from the Institute for Solid State Electronics, Technical University of Vienna, Vienna, Austria, in 1998.

Since 1998, he has been with Siemens AG, Corporate Technology, Munich, Germany. His research activities are in the field of compact power electronics and high-temperature electronics. 